\title{
General Psychiatry Burden of care in caregivers of patients with alcohol use disorder and schizophrenia and its association with anxiety, depression and quality of life
}

\author{
Sneha Vadher (D) , ${ }^{1}$ Rishi Desai (D) , ${ }^{1}$ Bharat Panchal, ${ }^{1}$ Ashok Vala, ${ }^{1}$ \\ Imran Jahangirali Ratnani, ${ }^{1}$ Mihir P Rupani, ${ }^{2}$ Kinjal Vasava ${ }^{1}$
}

To cite: Vadher S, Desai $R$, Panchal B, et al. Burden of care in caregivers of patients with alcohol use disorder and schizophrenia and its association with anxiety, depression and quality of life. General Psychiatry 2020;33:e100215. doi:10.1136/ gpsych-2020-100215

Received 27 February 2020 Revised 26 April 2020 Accepted 20 May 2020

\section{Check for updates}

(C) Author(s) (or their employer(s)) 2020. Re-use permitted under CC BY-NC. No commercial re-use. See rights and permissions. Published by BMJ.

${ }^{1}$ Department of Psychiatry, Government Medical College Bhavnagar, Bhavnagar, Gujarat, India

${ }^{2}$ Department of Community Medicine, Government Medical College Bhavnagar, Bhavnagar, Gujarat, India

Correspondence to

Dr Ashok Vala;

drvala175@gmail.com

\section{ABSTRACT}

Background Caregivers play a pivotal role in providing care for mentally ill patients. Increase in caregiver burden can make them vulnerable to mental illness themselves. Aims We assessed the severity of burden of care and its association with depression, anxiety and quality of life among caregivers of patients with alcohol use disorder (AUD) and schizophrenia.

Methods This was an observational, cross-sectional, single-centred study of 50 consecutive caregivers of patients with AUD and schizophrenia. Participants were recruited from the psychiatry outpatient department of a tertiary care hospital between January and June 2017. The caregivers were further assessed by demographic details, Hospital Anxiety Depression Scale for assessment of depression and anxiety, Zarit Burden Interview for assessment of caregiver burden and WHO Quality Of LifeBREF for assessment of quality of life. Statistical data were analysed using GraphPad InStat V.3.06 (California). Multiple linear regression analysis was applied to identify the predictors of caregiver burden.

Results Burden of care experienced by caregivers of patients with AUD is as high as that of caregivers of patients with schizophrenia $(U=1142.5, p=0.46)$. Caregivers experiencing high burden of care are likely to have symptoms of anxiety $(\mathrm{U}=22, \mathrm{p}<0.001)$, depression $(\mathrm{U}=32, \mathrm{p}<0.001)$ and poor quality of life $(\mathrm{U}=84.5$, $p<0.001)$. Female caregivers are likely to experience higher burden of care $(\mathrm{U}=819.5, \mathrm{p}=0.006)$. For caregivers of patients with schizophrenia, anxiety, environmental health, socioeconomic status and patients' occupation can predict burden of care, while for caregivers of patients with AUD, depression and environmental health can predict burden of care.

Conclusion Our study suggests that caregivers of patients with AUD experience burden of care as high as that of caregivers of patients with schizophrenia. Caregivers with high burden of care are more likely to have depression, anxiety and poor quality of life.

Trial registration number CTRI/2017/03/008224.

\section{INTRODUCTION}

Family is the basic unit of the society and is extensively involved in the well-being of kith and kin. ${ }^{1}$ With the alarming rise in the incidence of mental illness across the globe, there is a proportionate rise in the burden of care among caregivers of those who are mentally ill. Aside from providing help with activities of daily living, families also provide emotional, social and financial support to individuals with mental illness. ${ }^{23}$ Being the first ones to come in contact with the person with mental illness, family members also have to face the stigma, shame and prejudice from the society. Chronic mental illness in one family member may paralyse the life of others in the family and restrict their avenues for leisure, socialisation and employment. This puts them at greater risk of suffering from mental illness. ${ }^{34}$

Alcohol use disorder (AUD) is a group of behavioural and physical symptoms that can include withdrawal, tolerance and craving. ${ }^{5}$ Often considered a family disease, AUD also takes a toll on the lives of family members. ${ }^{6}$ The increase in unpredictable and unreliable behaviour in individuals with AUD translates into stress and strain in caregivers. ${ }^{7}$ This leads to defective coping and increases their vulnerability to mental illness. ${ }^{8}$ Family bears the brunt of domestic violence of all forms, that is, physical, verbal and sexual. ${ }^{9}$ Low marital satisfaction, poverty and embarrassment are other impediments to the well-being of caregivers. This ultimately pushes the family to penury. ${ }^{10}$

Schizophrenia refers to the dysfunction in cognitive, behavioural and emotional domain, ${ }^{5}$ and is an extremely damaging disorder that leads to long-term disability. It onerously affects family members. ${ }^{11}$ Caregiving restricts family members' freedom, personal space and social activities. Encouragement of deinstitutionalisation in mental health policies leads the family to being caught unprepared to take care of members 
with schizophrenia, which in turn increases their burden. ${ }^{9}$ Studies conducted previously have reported an increase in the incidence of depression, anxiety and stress among caregivers of individuals with schizophrenia. ${ }^{12} 13$

The dearth of data comparing the burden of care among caregivers of individuals with AUD and schizophrenia led us to pursue this study. Our study aims to assess the severity of burden of care and its association with depression, anxiety and quality of life among caregivers of individuals with schizophrenia and AUD.

\section{MATERIALS AND METHODS}

This is an observational, cross-sectional, single-centred study. Schizophrenia and AUD were diagnosed according to the Diagnostic and Statistical Manual of Mental Disorders-5. Fifty consecutive caregivers of patients with schizophrenia and AUD were recruited from the psychiatry outpatient department of a tertiary care hospital between January and June 2017. Patients who had been diagnosed with schizophrenia or AUD for more than 1 year, caregivers older than 18 years, caregivers living with the patient for at least 1 year before recruitment to this study, caregivers who have been closely involved in patients' activities of daily living, healthcare and social interaction, and those who provided consent to participate in the study, were included. Any psychotic condition other than schizophrenia, alcohol use in patients with schizophrenia, caregivers with severe mental illnesses, such as schizophrenia or bipolar mood disorder, those unable to give verbal replies, and those who do not give consent to participate in the study, were excluded. The purpose of the study was explained to the participants and written informed consent was obtained from them. The pro forma for participants contained patients' and caregivers' demographic details, the Hospital Anxiety Depression Scale (HADS), Zarit Burden Interview (ZBI) and WHO Quality of Life-BREF (WHOQOL-BREF) scales to be applied to caregivers. Interview with the participants was done in their vernacular language. Caregivers were interviewed separately from the patients to increase comfort and avoid any bias due to the presence of patients. Maintenance of anonymity and confidentiality of participants was ensured. Figure 1 depicts the flowchart of the study method.

The HADS is a 14-item, 4-point Likert scale designed to assess anxiety and depression in a hospital setting. It

56 caregivers of schizophrenia and 58 caregivers of alcohol use disorder were enrolled into study between January to June, 2017 (patients who had been diagnosed as Schizophrenia or AUD for more than 1 year, caregiver is above 18 years of age, caregiver is living with patient for at least 1 year, caregiver has been closely involved in his/her activities of daily living, health care, and social interaction, caregiver has given consent for the study)

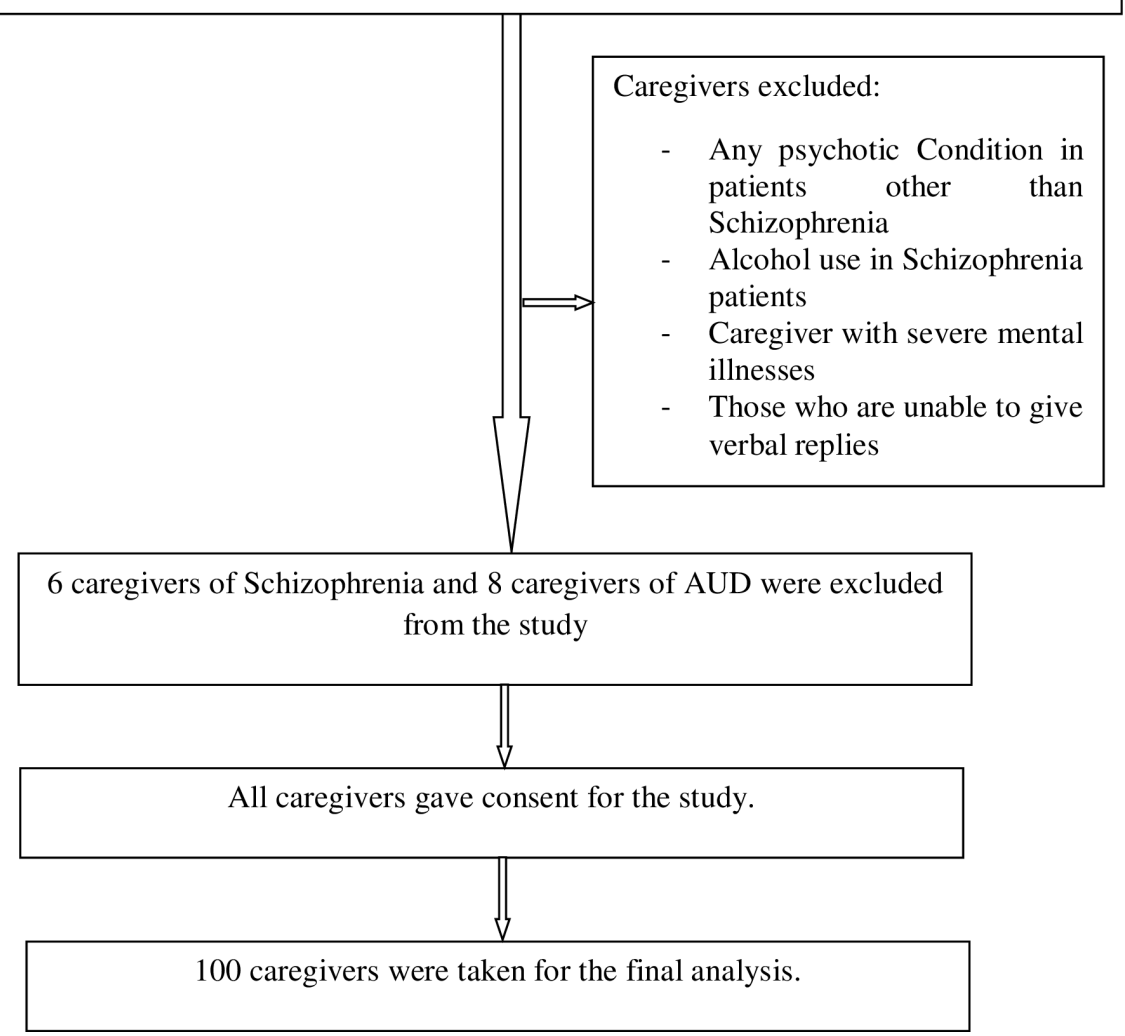

Figure 1 Flowchart of the study method. AUD, alcohol use disorder. 
comprises two subscales, each containing seven questions to assess anxiety and depression, respectively. It measures symptoms over the past 1 week and contains both positively and negatively constructed items. The even-numbered items measure depression, while the odd-numbered items measure anxiety. The responses for each question range from 0 to 4 . The total possible score ranges from 0 to 21 for each subscale. Higher scores on each subscale suggest more severe symptoms. A total subscale score of 0-7 denotes no symptoms, 8-10 denotes borderline abnormal case, and 11-21 denotes abnormal case of depression or anxiety. A cut-off score of 8 denotes abnormal case. The HADS shows good internal reliability, test-retest reliability, concurrent validity, sensitivity and specificity. ${ }^{14}$ In the present study, it has a Cronbach's alpha coefficient of 0.977 .

The ZBI is a 22-item, 5-point Likert scale developed by Zarit $e t a l^{15}$ to measure the burden of care experienced by caregivers of individuals with mental illness. The responses for each question range from 0 (never) to 4 (nearly always). The total possible score ranges from 0 to 88 . Higher scores on the scale denote higher burden of care experienced by caregivers of individuals with mental illness. A total score of 0-20 represents little or no burden, 21-40 represents mild to moderate burden, 41-60 represents moderate to severe burden and 61-88 represents severe burden. The ZBI has been found to have good internal consistency, construct validity and test-retest reliability. ${ }^{15}$ In the present study, it has a Cronbach's alpha coefficient of 0.978 . A cut-off score of 40 was used to distinguish between low burden and high burden following recommendations of an earlier study. ${ }^{16}$

The WHOQOL-BREF questionnaire is a 26-item, 5-point Likert scale developed by the WHO to assess quality of life over the past 2 weeks. It assesses quality of life in four domains: physical health (seven items), psychological health (six items), social relationships (three items) and environmental health (eight items). It also consists of two other items for overall quality of life and general health. Each item on the scale is rated from 1 to 5; scores of items for each domain are summed up to determine a raw score for each domain. Higher scores on the scale are indicative of higher quality of life. The WHOQOL-BREF domain scores demonstrate good discriminant validity, content validity, internal consistency and test-retest reliability. ${ }^{17}$ In the present study, it has a Cronbach's alpha coefficient of 0.980 .

\section{Statistical analysis}

Qualitative data are expressed as percentages, while quantitative data are expressed as mean (SD). Proportions of participants were compared using the $\chi^{2}$ test. The Kolmogorov-Smirnov normality test was applied. Scores on HADS, ZBI and WHOQOL-BREF scales that followed normality test were compared using Student's two-tailed t-test, while scores that did not follow normality test were compared using Mann-Whitney test. Statistical analysis was done using GraphPad InStat V.3.06 (San Diego,
California, USA). Multiple linear regression analysis was applied to identify the predictors of caregiver burden. Here, the ZBI score was taken as the outcome variable, and the anxiety and depression subscale scores of HADS, domain scores of WHOQOL-BREF and the demographic variables as predictor variables. A $p$ value $\leq 0.05$ was considered statistically significant.

\section{RESULTS}

\section{Demographic characteristics}

The demographic characteristics of caregivers and patients with schizophrenia and AUD are shown in table 1.

The mean duration of illness was longer in patients with AUD than in patients with schizophrenia, while the mean duration of treatment was longer in patients with schizophrenia than in patients with AUD. Hence, these two variables were not comparable.

Few caregivers of patients with AUD and schizophrenia suffered from adjustment disorder or anxiety disorder.

\section{Level of burden of care and its association with other variables}

Table 2 shows that caregivers of individuals with AUD with high burden of care are likely to have higher scores in the depression subscale $(\mathrm{U}=48, \mathrm{p}<0.001)$ and anxiety subscale $(\mathrm{U}=36, \mathrm{p}<0.001)$ of HADS, and lower scores in the physical health domain $(\mathrm{U}=129.5, \mathrm{p}=0.002)$, psychological health domain $(\mathrm{U}=104, \mathrm{p}<0.001)$, social relationships domain $(\mathrm{U}=141, \mathrm{p}=0.004)$ and environmental health domain $(\mathrm{U}=88, \mathrm{p}<0.001)$. Caregivers of individuals with schizophrenia with high burden of care are likely to have higher scores in the depression subscale $(\mathrm{U}=32, \mathrm{p}<0.001)$ and anxiety subscale $(\mathrm{U}=22, \mathrm{p}<0.001)$ of HADS, and lower scores in the physical health domain ( $\mathrm{U}=84.5, \mathrm{p}<0.001)$, psychological health domain $(\mathrm{U}=68.5$, $\mathrm{p}<0.001)$, social relationships domain $(\mathrm{U}=115, \mathrm{p}<0.001)$ and environmental health domain $(\mathrm{U}=45.5, \mathrm{p}<0.001)$.

\section{Comparison of variables between schizophrenia and AUD}

As shown in table 3 , there was no statistical difference in scores on ZBI $(\mathrm{U}=1142.5, \mathrm{p}=0.46)$, depression ( $\mathrm{U}=973$, $\mathrm{p}=0.056)$ and anxiety $(\mathrm{U}=1087, \mathrm{p}=0.26)$ subscales of HADS, and all domains of WHOQOL-BREF between caregivers of patients with schizophrenia and AUD.

\section{Effect of gender on burden of care and other variables}

Table 4 shows that female caregivers of patients with AUD are likely to have higher scores on the ZBI scale $(\mathrm{t}=2.42$, $\mathrm{p}=0.01)$ and on the anxiety subscale of HADS $(t=2.52$, $\mathrm{p}=0.01$ ), and lower scores on the physical health domain $(\mathrm{t}=3.21, \mathrm{p}=0.002)$, psychological health domain $(\mathrm{t}=3.44$, $\mathrm{p}=0.001)$, social relationships domain $(\mathrm{U}=128, \mathrm{p}=0.04)$ and environmental health domain $(\mathrm{t}=4.43, \mathrm{p}<0.001)$. Female caregivers of patients with schizophrenia are likely to have higher scores on the ZBI $(\mathrm{U}=198.5, \mathrm{p}=0.04)$ and the anxiety subscale of HADS $(\mathrm{U}=183, \mathrm{p}=0.02)$, 
Table 1 Demographic characteristics and other factors of caregivers and patients with schizophrenia and AUD.

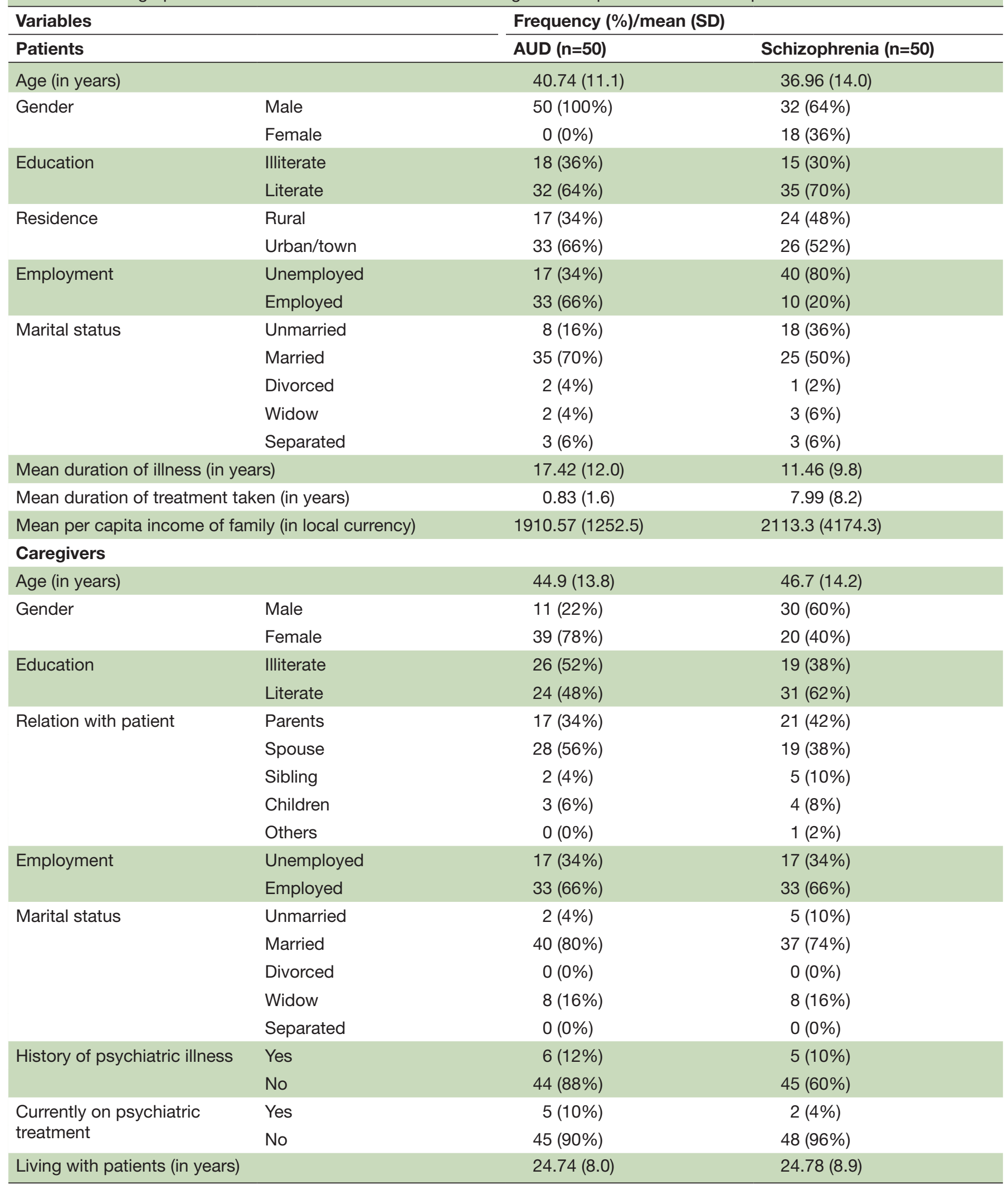

AUD, alcohol use disorder. 
Table 2 Comparison of HADS and WHOQOL-BREF scores between caregivers with high burden and low burden of care of patients with alcohol use disorder and schizophrenia.

\begin{tabular}{|c|c|c|c|c|}
\hline & $\begin{array}{l}\text { Caregivers with } \\
\text { low burden }\end{array}$ & $\begin{array}{l}\text { Caregivers with } \\
\text { high burden }\end{array}$ & & \\
\hline & ZBI score $\leq 40$ & ZBI score > 40 & $\begin{array}{l}\text { Mann-Whitney U } \\
\text { value }\end{array}$ & $P$ value \\
\hline \multicolumn{5}{|l|}{ Alcohol use disorder } \\
\hline & $\mathrm{n}=17$ & $n=33$ & & \\
\hline \multicolumn{5}{|l|}{ HADS scores } \\
\hline Depression & $7.4(5.3)$ & $16.2(3.7)$ & 48 & $<0.001$ \\
\hline Anxiety & $6.8(4.8)$ & $15.8(3.8)$ & 36 & $<0.001$ \\
\hline \multicolumn{5}{|l|}{ WHOQOL-BREF score } \\
\hline Physical health & $57.3(15.8)$ & $44.8(12.4)$ & 129.5 & 0.002 \\
\hline Psychological health & $61.2(18.1)$ & $39.7(17.6)$ & 104 & $<0.001$ \\
\hline Social relationships & $65.6(27.4)$ & $38.1(28.4)$ & 141 & 0.004 \\
\hline Environmental health & $68.5(24.3)$ & $39.4(21.6)$ & 88 & $<0.001$ \\
\hline \multicolumn{5}{|l|}{ Schizophrenia } \\
\hline & $\mathrm{n}=17$ & $n=33$ & & \\
\hline \multicolumn{5}{|l|}{ HADS score } \\
\hline Depression & $5.17(3.6)$ & $14.2(4.5)$ & 32 & $<0.001$ \\
\hline Anxiety & $5.29(3.7)$ & $14.5(3.9)$ & 22 & $<0.001$ \\
\hline \multicolumn{5}{|l|}{ WHOQOL-BREF score } \\
\hline Physical health & $60.9(9.2)$ & $43.0(14.9)$ & 85 & $<0.001$ \\
\hline Psychological health & $66.4(16.8)$ & $39.1(15.9)$ & 69 & $<0.001$ \\
\hline Social relationships & $71.5(27.9)$ & $45.9(24.5)$ & 115 & $<0.001$ \\
\hline Environmental health & $77.9(14.5)$ & $39.6(21.3)$ & 46 & $<0.001$ \\
\hline
\end{tabular}

Data are presented as mean (SD).

Groups were compared by Mann-Whitney test.

$\mathrm{P}<0.05$ is considered statistically significant.

HADS, Hospital Anxiety Depression Scale; WHOQOL-BREF, WHO Quality of Life-BREF; ZBI, Zarit Burden Interview.

Table 3 Results of comparison of HADS, ZBI and WHOQOL-BREF scores between schizophrenia and alcohol use disorder groups.

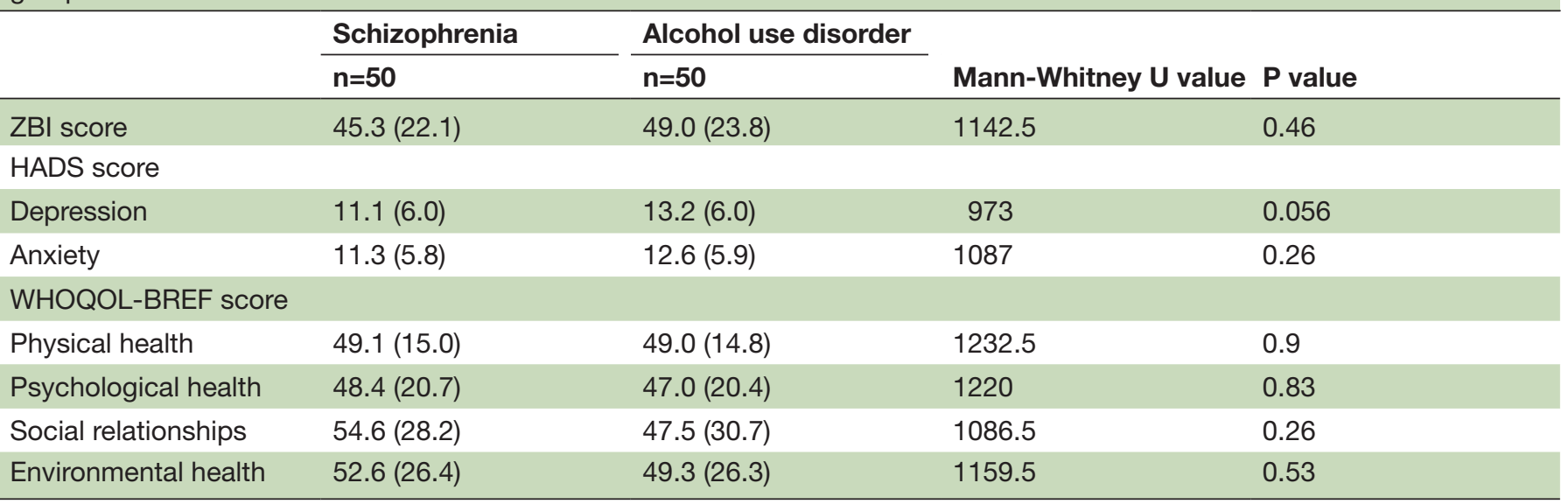

Data are presented as mean (SD).

Groups were compared by Mann-Whitney test.

$\mathrm{P}<0.05$ is considered statistically significant.

HADS, Hospital Anxiety Depression Scale; WHOQOL-BREF, WHO Quality of Life-BREF; ZBI, Zarit Burden Interview. 
Table 4 Comparison of ZBI, HADS and WHOQOL-BREF scores between male and female caregivers of patients with schizophrenia and alcohol use disorder.

\begin{tabular}{|c|c|c|c|c|c|c|c|c|}
\hline & \multicolumn{4}{|c|}{ Alcohol use disorder } & \multicolumn{4}{|c|}{ Schizophrenia } \\
\hline & \multirow{2}{*}{$\begin{array}{l}\begin{array}{l}\text { Male } \\
\text { caregivers }\end{array} \\
\mathrm{n}=11\end{array}$} & \multirow{2}{*}{$\begin{array}{l}\begin{array}{l}\text { Female } \\
\text { caregivers }\end{array} \\
\mathrm{n}=\mathbf{3 9}\end{array}$} & \multirow[t]{2}{*}{$\begin{array}{l}\mathrm{U} \text { value/t } \\
\text { value }\end{array}$} & \multirow[t]{2}{*}{$P$ value } & \multirow{2}{*}{$\begin{array}{l}\begin{array}{l}\text { Male } \\
\text { caregivers }\end{array} \\
\mathrm{n}=\mathbf{3 0}\end{array}$} & \multirow{2}{*}{$\begin{array}{l}\begin{array}{l}\text { Female } \\
\text { caregivers }\end{array} \\
\mathrm{n}=20\end{array}$} & \multirow{2}{*}{$\begin{array}{l}\mathrm{U} \text { value/t } \\
\text { value }\end{array}$} & \multirow[t]{2}{*}{$P$ value } \\
\hline & & & & & & & & \\
\hline ZBI score & $34.36(28.2)$ & $53.17(21.0)$ & $2.42^{*}$ & $0.01^{*}$ & $41.06(22.9)$ & $51.65(19.6)$ & 198.5 & 0.04 \\
\hline \multicolumn{9}{|l|}{ HADS score } \\
\hline Depression & $9.63(7.7)$ & $14.3(5.1)$ & 135 & 0.06 & $10.2(6.1)$ & $12.6(5.7)$ & $1.39^{*}$ & $0.17^{*}$ \\
\hline Anxiety & $8.90(6.4)$ & $13.7(5.4)$ & $2.52^{\star}$ & $0.01^{*}$ & $9.96(6.0)$ & $13.5(5.0)$ & 183 & 0.02 \\
\hline \multicolumn{9}{|l|}{ WHOQOL-BREF score } \\
\hline Physical health & $60.71(12.0)$ & $45.78(13.9)$ & $3.21^{*}$ & $0.002^{*}$ & $52.38(13.8)$ & $44.28(17.4)$ & $1.83^{*}$ & $0.07^{\star}$ \\
\hline Psychological health & $64.01(17.9)$ & $42.30(18.6)$ & $3.44^{*}$ & $0.001^{*}$ & $51.80(21.0)$ & $43.33(19.7)$ & $1.43^{*}$ & $0.15^{\star}$ \\
\hline Social relationships & $66.66(32.7)$ & $42.09(28.3)$ & 128 & 0.04 & $59.06(25.9)$ & $43.1(24.8)$ & $1.57^{\star}$ & $0.12^{*}$ \\
\hline Environmental health & $75.85(23.8)$ & $41.90(22.0)$ & $4.43^{*}$ & $<0.001^{*}$ & $41.06(22.9)$ & $51.65(19.6)$ & $2.16^{*}$ & $0.03^{*}$ \\
\hline
\end{tabular}

Data are presented as mean (SD).

*Denotes that data followed the normality test and so are interpreted by unpaired t-test, and thus $t$ value has been mentioned, while the rest of the groups were compared by Mann-Whitney test. $\mathrm{P}<0.05$ is considered statistically significant.

HADS, Hospital Anxiety Depression Scale; WHOQOL-BREF, WHO Quality of Life-BREF; ZBI, Zarit Burden Interview.

and lower scores on the environmental health domain $(\mathrm{t}=2.16, \mathrm{p}=0.03)$.

\section{Predictors of burden of care}

Linear regression analysis was applied to identify the predictors of burden of care using the stepwise technique. All predictors found to be significant in the univariate analysis were then entered into the multivariate analysis. In the present model, ZBI score was considered as the outcome variable.

The multiple regression model for caregivers of individuals with AUD with all predictors produced an adjusted $\mathrm{R}^{2}=0.784$, which stipulates that $78.4 \%$ variance in the outcome variable can be explained by the predictors. This model was also significant in prediction $(F(2$, $48)=90.023, p<0.001)$. Similarly, the multiple regression model for caregivers of individuals with schizophrenia with all predictors produced an adjusted $\mathrm{R}^{2}=0.757$, which stipulates that $75.7 \%$ variance in the outcome variable can be explained by the predictors. This model was significant in the prediction $(F(4,46)=39.151, \mathrm{p}<0.001)$.

For the ZBI score of caregivers of patients with AUD, after two-step linear regression model, depression score on HADS $(\mathrm{B}=2.780, \mathrm{p}<0.001)$ and environmental health domain score on WHOQOL-BREF $(B=-0.224, p=0.008)$ were found to be significant predictors of burden of care (table 5). For the ZBI score of caregivers of patients with schizophrenia, after four-step linear regression model, anxiety score on HADS $(\mathrm{B}=2.032, \mathrm{p}<0.001)$, environmental health domain score on WHOQOL-BREF $(\mathrm{B}=-0.326, \mathrm{p}=0.003)$, socioeconomic status of caregiver $(\mathrm{B}=0.001, \mathrm{p}=0.022)$ and patients' occupation $(\mathrm{B}=-9.009$, $\mathrm{p}=0.024$ ) were found to be significant predictors of burden of care (table 5).
As can be seen in table 5, scores on the depression subscale of HADS had positive weightage, so caregivers of individuals with AUD with higher scores on this scale are expected to have higher ZBI score, while scores on the environmental health domain of WHOQOL-BREF had negative weightage in the model, so caregivers of individuals with AUD with low scores on the environmental health domain are expected to have higher ZBI score. Similarly, anxiety score on HADS and the socioeconomic status of caregivers of individuals with schizophrenia had significant positive regression weightage, stipulating that caregivers of individuals with schizophrenia with higher scores on the anxiety subscale of HADS and caregivers of individuals with schizophrenia with higher socioeconomic status are expected to have higher ZBI score. The environmental health domain score of WHOQOLBREF and patients' occupation had a significant negative weightage, indicating that caregivers of individuals with schizophrenia with lower scores on the environmental health domain and with unemployed patients are expected to have higher ZBI score.

Depression score on HADS is the strongest predictor of burden of care in caregivers of individuals with AUD (table 5), while unemployed patient with schizophrenia is the strongest predictor of burden of care in caregivers, as can be seen in table 5 .

- Working model to predict ZBI score for caregivers of individuals with AUD and its application to the next caregiver is as follows:

ZBI score $=23.238+2.780$ (depression score $)-0.224$ (environmental health domain score).

- Working model to predict ZBI score for caregivers of individuals with schizophrenia and its application to the next caregiver is as follows: 
Table 5 Linear regression analysis of predictors of burden of care in caregivers of individuals with alcohol use disorder and schizophrenia.

\begin{tabular}{|c|c|c|c|c|c|}
\hline \multirow[b]{2}{*}{ Model } & \multicolumn{2}{|c|}{ Unstandardised coefficients } & \multirow{2}{*}{$\begin{array}{l}\text { Standardised } \\
\text { coefficients } \\
\text { Beta }\end{array}$} & \multirow[b]{2}{*}{$\mathbf{t}$} & \multirow[b]{2}{*}{ Significance } \\
\hline & B & SE & & & \\
\hline \multicolumn{6}{|l|}{ Alcohol use disorder } \\
\hline (Constant) & 23.238 & 8.141 & & 2.854 & 0.006 \\
\hline Depression subscale of HADS & 2.780 & 0.355 & 0.705 & 7.833 & $<0.001$ \\
\hline $\begin{array}{l}\text { Environmental health domain of } \\
\text { WHOQOL-BREF }\end{array}$ & -0.224 & 0.081 & -0.247 & -2.752 & 0.008 \\
\hline \multicolumn{6}{|l|}{ Schizophrenia } \\
\hline (Constant) & 48.159 & 11.227 & & 4.290 & $<0.001$ \\
\hline Anxiety subscale of HADS & 2.032 & 0.449 & 0.540 & 4.522 & $<0.001$ \\
\hline $\begin{array}{l}\text { Environmental health domain of } \\
\text { WHOQOL-BREF }\end{array}$ & -0.326 & 0.103 & -0.390 & -3.157 & 0.003 \\
\hline Socioeconomic status & 0.001 & 0.000 & 0.177 & 2.377 & 0.022 \\
\hline Patient's occupation & -9.009 & 3.859 & -0.165 & -2.334 & 0.024 \\
\hline
\end{tabular}

Adjusted $\mathrm{R}^{2}$ for caregivers of patients with alcohol use disorder $=0.784$.

Adjusted $\mathrm{R}^{2}$ for caregivers of patients with schizophrenia $=0.757$.

$\mathrm{P}<0.05$ is considered statistically significant.

HADS, Hospital Anxiety Depression Scale; WHOQOL-BREF, WHO Quality of Life-BREF.

ZBI score $=48.159+2.032$ (anxiety score) -0.326 (environmental health domain score) +0.001 (socioeconomic status) - 9.009 (patient's occupation).

\section{DISCUSSION}

\section{Main findings}

Our results suggest that caregivers of patients with schizophrenia are likely to experience a significant burden of care. Schizophrenia is a chronic illness, which might hamper the insight of an individual to a great extent. The burden of care in caregivers of patients suffering from schizophrenia may be attributed to the above factors at large. However, several other factors that play an important role in increasing the burden of care include taking care of the patient's grooming, hygiene, daily needs, medications, and dealing with exacerbation and relapse of illness. This can make the caregiver feel burdened. These findings were corroborated by other studies. ${ }^{18-20}$

As can be seen in tables 2 and 5 , caregivers of patients with schizophrenia with higher burden of care are likely to have depression, anxiety and poor quality of life. Also burden of care in caregivers can be predicted by anxiety and environmental quality of life. This can be because the burden of caring affects caregivers' ability to cope with illness. Longer duration of illness and caregiving become chronic stressors for caregivers. Social isolation may follow, leading to increased stress and making them vulnerable to depression and anxiety. Moreover, caregivers are flooded with patient and family responsibilities and are burdened with caregiving duties and persistent worries about their patients. This will result in withdrawal from the society and leisure activities, leading to poor quality of life. Similar results were found in previous studies. $^{121321}$

Table 5 suggests that burden of care in caregivers of patients with schizophrenia can be predicted by the employment status of the patient. A possible explanation for this can be that owing to unemployment, patients and caregivers are forced into a life of penury. They spend more time at home and so caregivers are burdened with caregiving tasks, in comparison with patients who are employed where caregivers get more time of rest and relief while patients are away for work. Monetary scarcity further increases the burden. Our findings were substantiated in earlier studies. ${ }^{41-23}$

Our results show that caregivers of patients with AUD are likely to experience significant burden of care. Repeated quarrels, verbal and physical abuse by the person with AUD, and seclusion of caregivers from other family members and society significantly impact their physical and mental health. These can lead to increased burden in caregivers of patients with AUD. Other studies also showed similar results. ${ }^{2425}$

Caregivers of patients with AUD with higher burden of care are likely to have depression and anxiety, and burden of care can be predicted by anxiety (tables 2 and $5)$. This can be explained on the basis that health-related issues among caregivers themselves, violence committed by the patients, financial crisis, shame and stigma from the society towards alcoholics can lead to depression and anxiety in caregivers. These findings were confirmed in other studies. ${ }^{1026}$

Our study suggests that caregivers of patients with AUD are likely to have poor quality of life and that burden of 
care can be predicted by the environmental domain of quality of life (tables 2 and 5). This can be explained by the fact that AUD in one family member, especially when he/she is the sole breadwinner, may cause myriad problems for the caregivers. Some of these are occupational dysfunction, premature and compulsory retreat from jobs, solitude, changes in responsibilities, disruption of routine and social activities, and financial burden. All these can lead to poor quality of life among caregivers. Similar results were found in other studies. ${ }^{727}$

The results of our study show that there was no statistical difference in the burden of care experienced by caregivers of patients with schizophrenia and AUD (table 3). Caregivers of patients with AUD experience burden of care as high as that of caregivers of patients with schizophrenia. Other studies supported our results. ${ }^{28} 29$

As can be seen in table 4, female caregivers have higher caregiver burden and anxiety and poor quality of life. This might be due to female caregivers differing in their appraisal and in coping with stressors, and the lack of social support framework that caters to their needs. The sociocultural expectations imposed on them to adopt a caregiving role despite their difficulties add fuel to the fire. ${ }^{422}{ }^{23}$ Contradictory results were found in a few studies, where male caregivers experienced significant burden of care than female caregivers. ${ }^{28} 30$

\section{Limitations}

Although we have used validated scales of assessment, our study has some limitations, such as its small sample size, being a hospital-based study, participant recruitment from a single centre and being a cross-sectional study, cause-effect relationship cannot be established. The mean duration of illness and the mean duration of treatment were not adjusted in the univariate analysis. We have not taken into consideration the supporting network that our patients and their caregivers might have, which may influence burden of care. Further multicentric cohort studies with large sample size are required to obtain further insights into this subject.

\section{Implications}

Psychological problems of caregivers of patients with mental illness are not given enough attention or are ignored. There is a strong need to give proper attention towards caregivers' mental well-being to prevent mental illness and to identify early those who are at risk.

\section{CONCLUSION}

Caregivers of patients with AUD experience burden of care as high as that of caregivers of patients with schizophrenia. Caregivers with high burden of care are more likely to have depression, anxiety and poor quality of life. Female caregivers are likely to experience higher burden of care. For caregivers of patients with schizophrenia, anxiety, environmental health, socioeconomic status and patients' occupation can predict burden of care, while for caregivers of patients with AUD, depression and environmental health can predict burden of care.

Contributors SV did the planning, designing, analysis and interpretation of data, and helped in drafting and revising the work. RD helped in drafting and revising the work. BP helped in planning and designing the work. AV helped in planning and designing the work and critically revising the work. IJR helped in planning and designing the work, interpretation of data, and critically revising the work. MPR helped in the data analysis and in critically revising the work. KV helped in planning and designing the work.

Funding The authors have not declared a specific grant for this research from any funding agency in the public, commercial or not-for-profit sectors.

Competing interests None declared.

Patient consent for publication Not required.

Ethics approval Prior approval from the local ethics committee was taken before starting the study.

Provenance and peer review Not commissioned; externally peer reviewed.

Data availability statement No data are available.

Open access This is an open access article distributed in accordance with the Creative Commons Attribution Non Commercial (CC BY-NC 4.0) license, which permits others to distribute, remix, adapt, build upon this work non-commercially, and license their derivative works on different terms, provided the original work is properly cited, appropriate credit is given, any changes made indicated, and the use is non-commercial. See: http://creativecommons.org/licenses/by-nc/4.0/.

\section{ORCID iDs}

Sneha Vadher http://orcid.org/0000-0002-3090-6511

Rishi Desai http://orcid.org/0000-0002-5403-3487

\section{REFERENCES}

1 Bora K, Das A. Coping in caregivers of chronic schizophrenia and bipolar affective Disorder-A comparative study. J Med Sci Clin Res 2017;16:58-64.

2 Rospenda KM, Minich LM, Milner LA, et al. Caregiver burden and alcohol use in a community sample. J Addict Dis 2010;29:314-24.

3 Swapna B, Sudarshan CY, Begum S. Burden on caregivers in bipolar affective disorder and alcohol dependence. Int J Biol Med Res 2012;3:1992-7.

4 Gurram S, Macharapu R, Gade V, et al. Comparision of burden among care givers of patients with bipolar affective disorder and alcohol dependence syndrome. J Sci 2017;7:68-74.

5 American Psychiatric Association. Diagnostic and statistical manual of mental disorders (DSM-5®). Am Psychiat 2013.

6 Roth JD. Addiction as a family disease. J Groups Addict Recover 2010;5:1-3

7 Ganesh S, Mrs B, et al. Burden and Quality of Life among Care Givers of Persons with Alcohol Dependence Syndrome - A Hospital based Interventional Study. J Human Soc Sci 2017;22:20-8.

8 Darlami K, Ponnose R, Jose P. Caregiver's stress of psychiatric patients. J Univers Colleg Med Sci 2015;3:39-43.

9 Narasipuram S, Kasimahanti S. Quality of life and perception of burden among caregivers of persons with mental illness. Andhra Pradesh J Psychol Med 2012;13:99-103.

10 Kishor M, Pandit L, Raguram R. Psychiatric morbidity and marital satisfaction among spouses of men with alcohol dependence. Indian J Psychiatry 2013;55:360.

11 Yusuf AJ, Nuhu FT, Akinbiyi A. Caregiver burden among relatives of patients with schizophrenia in Katsina, Nigeria. South African J Psychiat 2009;15:5-7.

12 Gülseren L, Çam B, Karakoç B, et al. The perceived burden of care and its correlates in schizophrenia. Turk Psikiyatri Dergisi 2010;21.

13 El-Tantawy AM, Raya YM, Zaki AM. Depressive disorders among caregivers of schizophrenic patients in relation to burden of care and perceived stigma. Current Psychiatry 2010;17:15-25.

14 Zigmond AS, Snaith RP. The hospital anxiety and depression scale. Acta Psychiatr Scand 1983;67:361-70.

15 Zarit SH, Reever KE, Bach-Peterson J. Relatives of the impaired elderly: correlates of feelings of burden. Gerontologist 1980;20:649-55.

16 Stagg B, Larner AJ. Zarit burden interview: pragmatic study in a dedicated cognitive function clinic. Prog Neurol Psychiatry 2015;19:23-7. 
17 THE WHOQOL GROUP. Development of the world Health organization WHOQOL-BREF quality of life assessment. The WHOQOL group. Psychol Med 1998;28:551-8.

18 Chakrabarti S, Raj L, Kulhara P, et al. Comparison of the extent and pattern of family burden in affective disorders and schizophrenia. Indian J Psychiatry 1995;37:105.

19 Oza H, Parikh M, Vankar G. Comparison of caregiver burden in schizophrenia and obsessive-compulsive disorder. Arc Psychiat Psychother 2017;19:32-41.

20 Demirbas $\mathrm{H}$, Kizil ET. Burnout and related factors in caregivers of outpatients with schizophrenia. Insights on the Depression and Anxiety 2017;1:001-11.

21 Kumar S, Singh P, Shah R, et al. A study on assessment of family burden, quality of life and mental health in caregivers of patients with schizophrenia. Int Arc BioMed Clin Res 2017;3:53-7.

22 Swaroopachary RS, Kalasapati L, Ivaturi S, et al. Caregiver burden in alcohol dependence syndrome in relation to the severity of dependence. Archives of Mental Health 2018;19:19.

23 Adeosun II. Correlates of caregiver burden among family members of patients with schizophrenia in Lagos, Nigeria. Schizophr Res Treatment 2013;2013:1-7.
24 Vaishnavi R, Karthik MS, Balakrishnan R, et al. Caregiver burden in alcohol dependence syndrome. J Addict 2017;2017:1-6.

25 Paparrigopoulos T, Tzavellas E, Karaiskos D, et al. P01-61 family burden in alcohol dependence. European Psychiatry 2009;24:S449.

26 Gandhi R, Suthar M, Pal S, et al. Anxiety and depression in spouses of males diagnosed with alcohol dependence: a comparative study. Arc Psychiat Psychother 2017;19:51-6.

27 Gohil JG, Patel MK, Samani MJ. Quality of life and psychiatric morbidity in caregiver of alcohol dependence patients. IOSR 2016;15:98-101.

28 Hyder S, Chenganakkattil S, Babu J. Comparison of caregiver's burden in schizophrenia and alcohol dependence syndrome. $J$ Commun Health Manag 2016;3:213-6.

29 Chiddarwar S, Singh DA. A comparative study of marital distress and burden of illness in wives of patients with schizophrenia and alcohol dependence. Global J Res Analys 2018;7:45-8.

30 Adewuya AO, Owoeye OA, Erinfolami AR. Psychopathology and subjective burden amongst primary caregivers of people with mental illness in south-western Nigeria. Soc Psychiatry Psychiatr Epidemiol 2011;46:1251-6.

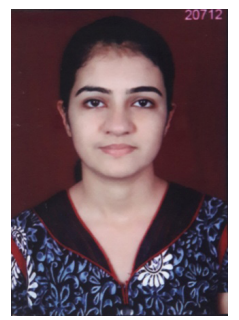

Dr Sneha Vadher completed her MBBS from Govt Medical College, Bhavnagar, India, in 2014. She obtained her degree of MD in Psychiatry from Govt Medical College, Bhavnagar, India, in 2018. She has been working as an assistant professor in the Department of Psychiatry at Pramukhswami Medical College, Karamsad, India, since 2019. Her research interest includes substance use disorder. Currently she is involved in research activity in Social Medial Addiction. 